\title{
Rectifier Low Order Harmonics Reduction Technique - Educational Approach
}

\author{
Yahya Asiri ${ }^{1}$ and Ibrahim El-Amin ${ }^{2}$ \\ "Saudi Arabian Oil Company "Saudi Aramco" \\ ${ }^{2}$ King Fahd University of Petroleum and Minerals \\ ${ }^{1}$ Saudi Arabia, ${ }^{2}$ Saudi Arabia,
}

\section{Introduction}

The rectifier is an electrical device that converts alternating current (AC) to direct current (DC), a process known as rectification. Rectifiers are usually built to supply polarized voltage power to the DC circuits. Rectifier applications rang from the DC biasing in mVolts to electronic components on the PC motherboards, to the kVolts of DC power supplies in the steel industry.

The wide utilization of DC rectifiers justifies studying the performance of theses electrical devices. Voltage and current harmonics are commonly associated with the function of power electronics devices including full wave rectifiers.

Harmonics in power systems have received increased attention in recent years with the widespread application of advanced solid-state power switching devices in a multitude of power electronic applications. Intensive study and research has concentrated on the input side to prevent the harmonics generated by switching devices to travel back to the network and disturb other connected loads. The voltage harmonics at the load side have not been treated widely in the published literature, although they share many effects with the input side harmonics. In both cases, these harmonic voltages can, in worst cases, result in the following:

- Wiring overheating.

- Capacitor bank damage.

- Electronic equipment malfunctioning.

- Communication interference.

- Resonance.

Furthermore, certain effects are associated with the output harmonics like vibrations and noises in electromagnetic loads such as DC motors. A chopping technique is the control method that will be applied to shape the output waveform; also, it will be used to devolve the mathematical model, perform Pspice simulation and build the experimental prototype. In this method, the output voltage of the bridge rectifier will be "chopped" in a sequential manner with a certain number of pulses and duty cycles to control the flow of current through the load. This technique offers a linear control for the DC component and redistributes the $\mathrm{AC}$ components (ripples). 


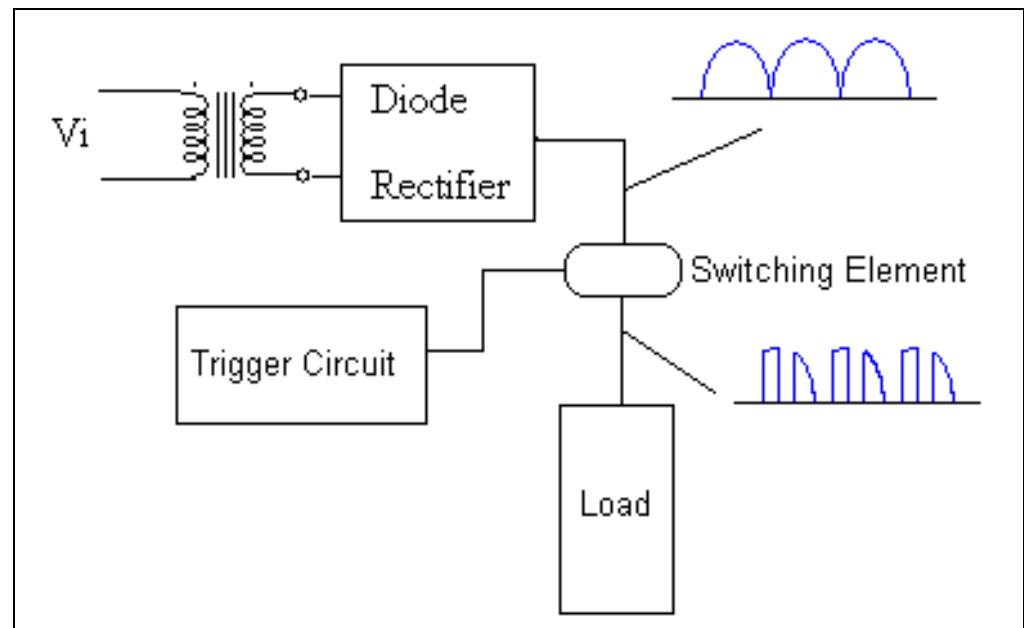

Fig. 1. The basic configuration of the controlled output bridge rectifier.

\section{Mathematical Modeling}

Based on the basic configuration of the controlled rectifier shown in Figure 1, we can start with the simplest case to calculate the coefficients of Fourier series as follows:

$\begin{array}{ll}\text { Period: } & \mathrm{T}=2 \pi \\ \text { Number of Pulses: } & \mathrm{N}=2 \\ \text { Duty Cycle: } & \mathrm{k}=50 \%\end{array}$

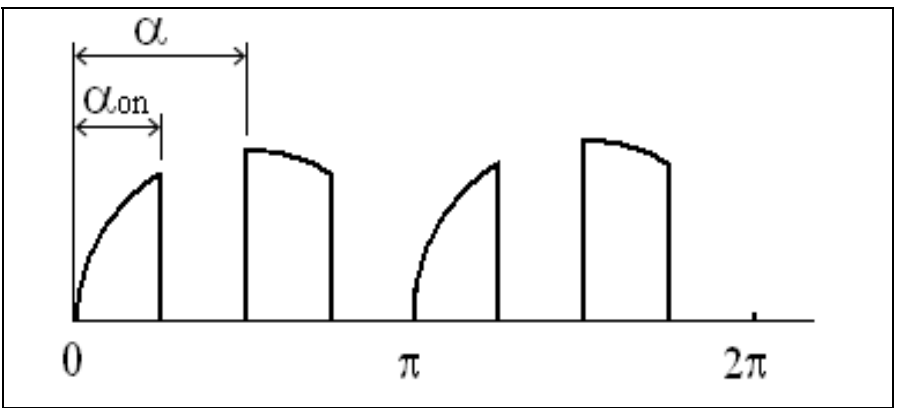

Fig. 2. 2-pulse shaped output of controlled rectifier with $50 \%$ dutycycle used to develop the mathematical model

The Fourier series of the output voltage is given by:

$$
\mathrm{V}_{\mathrm{o}}=\mathrm{V}_{\mathrm{dc}}+\sum_{\mathrm{n}=1}^{*}\left(\mathrm{a}_{\mathrm{n}} \sin \mathrm{n} \theta+\mathrm{b}_{\mathrm{n}} \cos \mathrm{n} \theta\right)
$$




$$
\begin{gathered}
\mathrm{V}_{\mathrm{dc}}=\frac{1}{2 \pi} \int_{0}^{2 \pi} \mathrm{V}_{\mathrm{P}} \sin \theta \mathrm{d} \theta \\
\mathrm{V}_{\mathrm{dc}}=\frac{\mathrm{V}_{\mathrm{P}}}{2 \pi}\left[\int_{0}^{\pi / 4} \sin \theta \mathrm{d} \theta+\int_{\pi / 2}^{3 \pi / 4} \sin \theta \mathrm{d} \theta\right] \\
=\frac{\mathrm{V}_{\mathrm{P}}}{\pi}
\end{gathered}
$$

Equation (3) could be generalized to accommodate the generic case when:

- $\quad \mathrm{N}=2,3,4,5,6 \ldots$ (integer numbers)

- $0<\mathrm{k} \leq 100 \%$

Thus,

$$
\mathrm{V}_{\mathrm{dc}}=\frac{\mathrm{V}_{\mathrm{P}}}{2 \pi} \sum_{\mathrm{I}=0}^{\mathrm{N}-1}\left(\cos \frac{\mathrm{I}}{\mathrm{N}} \pi-\cos \frac{\mathrm{k}+\mathrm{I}}{\mathrm{N}} \pi\right)+\frac{\mathrm{V}_{\mathrm{P}}}{2 \pi} \sum_{\mathrm{I}=\mathrm{N}}^{2 \mathrm{~N}-1}\left(\cos \frac{\mathrm{k}+\mathrm{I}}{\mathrm{N}} \pi-\cos \frac{\mathrm{I}}{\mathrm{N}} \pi\right)
$$

The resulted formula obtained in equation (5) could be verified by plugging in the conditions of an initial case of 2 pulses with $50 \%$ duty cycle; the result is matches with the value obtained by equation (4) above:

$$
\mathrm{V}_{\mathrm{dc}}=\mathrm{k} \frac{2 \mathrm{~V}_{\mathrm{P}}}{\pi}=\frac{\mathrm{V}_{\mathrm{P}}}{\pi}
$$

Coefficients of the Fourier series $\left(a_{n}\right.$ and $\left.b_{n}\right)$ could be calculated using the same generalized approach.

In this special case, the waveform is considered as an even function, thus the odd components do not exist.

$$
a_{1}=b_{1}=0
$$

For the cases when harmonic order: $\quad n \geq 2$

$$
a_{n}=\frac{2}{2 \pi} \int_{0}^{2 \pi} V_{P} \sin \theta \cos n \theta d \theta
$$

Evaluating the integration over the regions where the output voltage $\neq 0$ yields:

$$
\begin{aligned}
a_{n}= & \frac{V_{P}}{\pi} \sum_{I=0}^{N-1} \frac{1}{1-n^{2}}\left(\cos \frac{(1+n)(k+I)}{N} \pi+\cos \frac{(1+n) I}{N} \pi\right) \\
+ & \frac{V_{P}}{\pi} \sum_{I=N}^{2 N-1} \frac{1}{1-n^{2}}\left(\cos \frac{(1+n)(k+I)}{N} \pi+\cos \frac{(1+n) I}{N} \pi\right)
\end{aligned}
$$


Similarly, $b_{n}$ is calculated as follows:

$$
\begin{gathered}
\mathrm{b}_{\mathrm{n}}=\frac{2}{2 \pi} \int_{0}^{2 \pi} \mathrm{V}_{\mathrm{P}} \sin \theta \sin \mathrm{n} \theta \mathrm{d} \theta \\
\frac{\mathrm{V}_{\mathrm{P}}}{2 \pi} \sum_{\mathrm{I}=0}^{\mathrm{N}-1} \frac{1}{1-\mathrm{n}}\left(\sin \frac{(1-\mathrm{n})(\mathrm{k}+\mathrm{I})}{\mathrm{N}} \pi-\sin \frac{(1-\mathrm{n}) \mathrm{I}}{\mathrm{N}} \pi\right)- \\
\frac{\mathrm{V}_{\mathrm{P}}}{2 \pi} \sum_{\mathrm{I}=0}^{\mathrm{N}-1} \frac{1}{1+\mathrm{n}}\left(\sin \frac{(1+\mathrm{n})(\mathrm{k}+\mathrm{I})}{\mathrm{N}} \pi-\sin \frac{(1+\mathrm{n}) \mathrm{I}}{\mathrm{N}} \pi\right)- \\
\frac{\mathrm{V}_{\mathrm{P}}}{2 \pi} \sum_{\mathrm{I}=0}^{2 \mathrm{~N}-1} \frac{1}{1-\mathrm{n}}\left(\sin \frac{(1-\mathrm{n})(\mathrm{k}+\mathrm{I})}{\mathrm{N}} \pi-\sin \frac{(1-\mathrm{n}) \mathrm{I}}{\mathrm{N}} \pi\right)+ \\
\frac{\mathrm{V}_{\mathrm{P}}}{2 \pi-1} \sum_{\mathrm{I}=0}^{\mathrm{N}} \frac{1}{1+\mathrm{n}}\left(\sin \frac{(1+\mathrm{n})(\mathrm{k}+\mathrm{I})}{\mathrm{N}} \pi-\sin \frac{(1+\mathrm{n}) \mathrm{I}}{\mathrm{N}} \pi\right)
\end{gathered}
$$

The values of $V_{d c}, a_{n}$ and $b_{n}$ are used to reconstruct the output voltage by developing a calculation tool to obtain the values of $V_{o}$ as in equation (1). Plotting the voltage versus time resulted in the following waveforms:

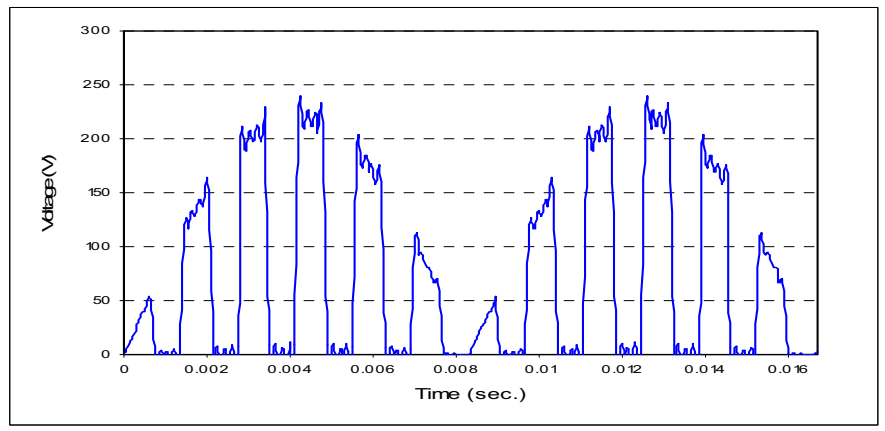

Fig. 3. The reconstructed output voltage as a summation of DC value and 100 harmonics.

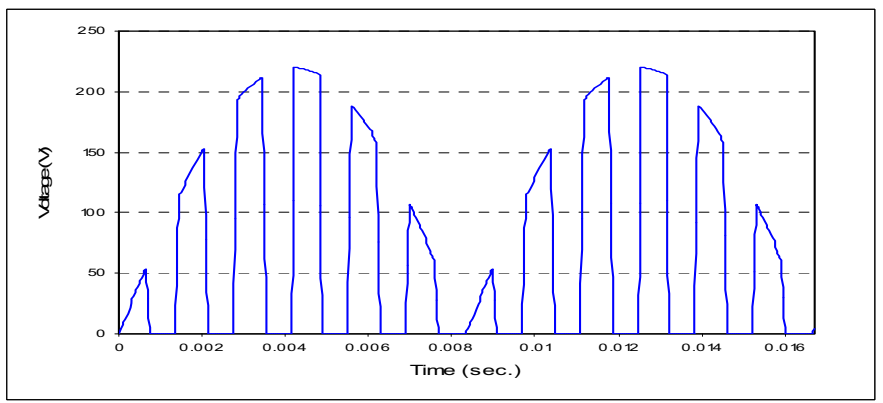

Fig. 4. The reconstructed output voltage as a summation of DC value and 1000 harmonics. 
The program generates the values of the AC components (harmonics) of the output voltage for both controlled and uncontrolled rectifiers.

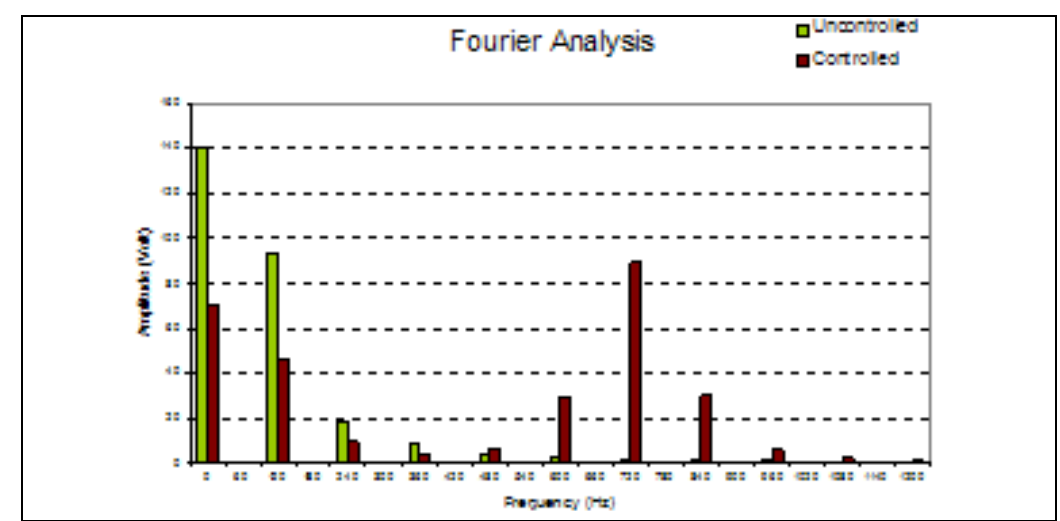

Fig. 5. Spectrum distribution for the calculated AC components of controlled and uncontrolled rectifiers.

Figure 5 shows a comparison of the spectrum distribution of an unchopped output and the output of a chopped rectifier with $\mathrm{k}=50 \%$ and $\mathrm{N}=6$. The spectrum of the chopped rectifier show fewer values of low-order harmonics but increased values at high frequencies. These high order harmonics are easy to filter.

\section{Pspice Simulation}

The basic circuit of the controlled rectifier is used for simulation using Pspice. Figure 6 shows the circuit representation adopted for Pspice simulation. The resistive load is selected in the circuit above to test the principle without the effect of inductive or capacitive loads that have lagging or leading effects on the voltage as well as current waveforms. Actually, the calculation tool is prepared to reflect such effects.

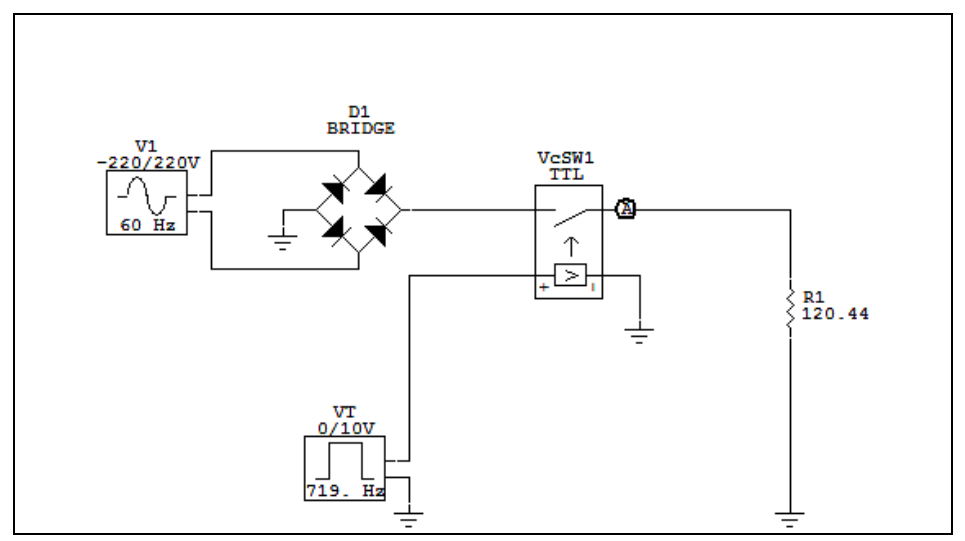

Fig. 6. Pspice simulation model 
Figure 7 shows the waveform of output voltage as simulated by Pspice. The package of CircuitMaker V6.2c circuit simulation program

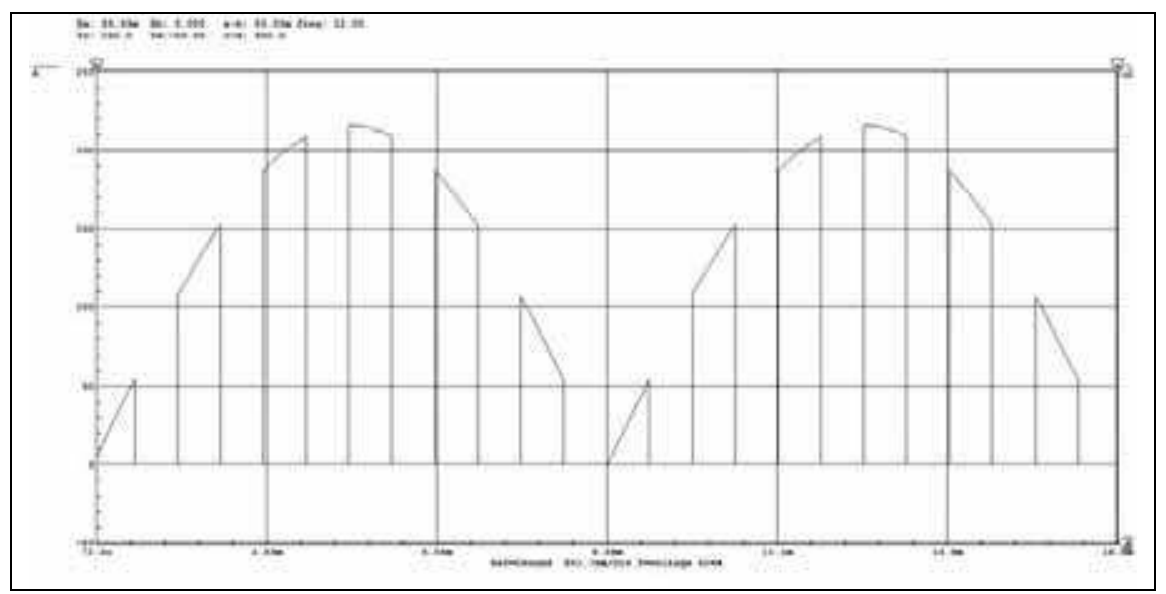

Fig. 7. Pspice output waveform for the controlled rectifier

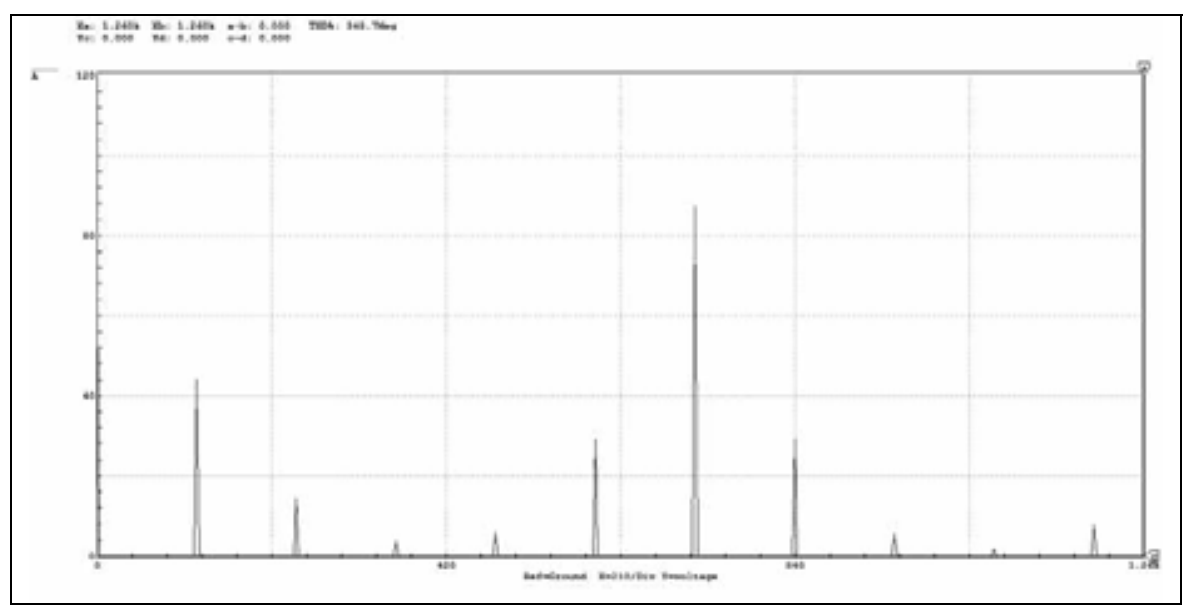

Fig. 8. Spectrum analyzer trace resulted by Fourier analysis tool of Pspice simulation

\section{Experimental Modeling}

To support the theoretical and simulation results, it is advisable to build an experimental prototype at the lab. to conduct a complete comparison of three different approaches. 


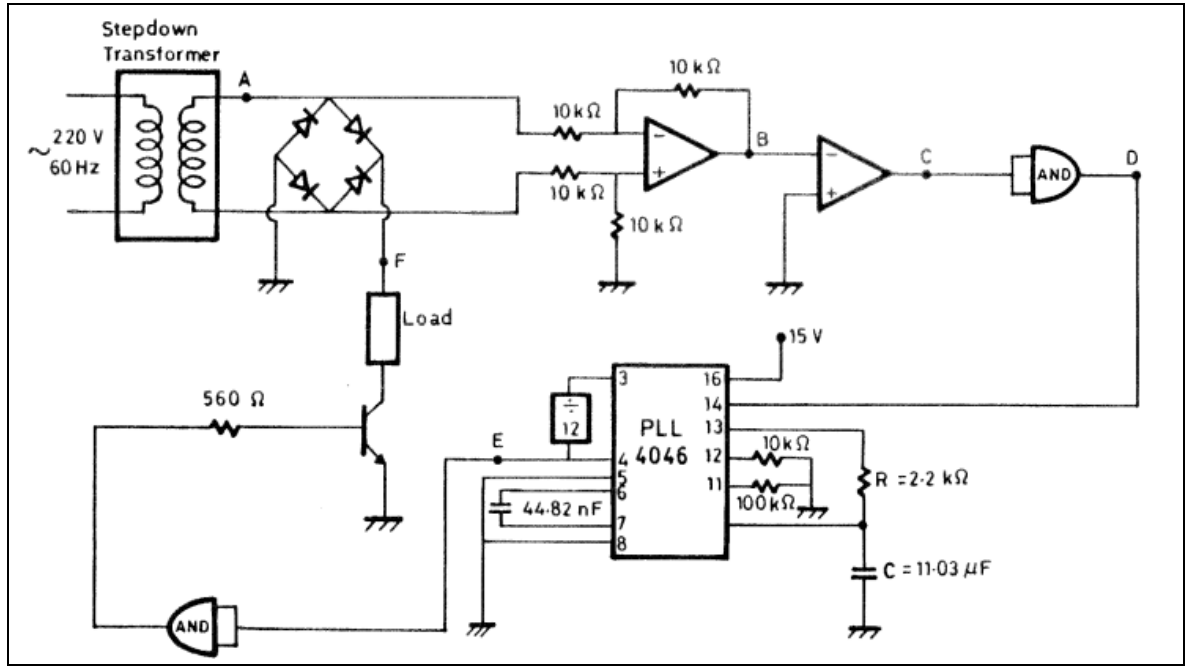

Fig. 9. Experimental prototype

Getting a synchronized trigger signal to switch on/off the power transistor (or GTO) that connects the load to the GND was the most important part in the prototyping. It is essential to fire the switching element at certain sequence with $\mathrm{ON}, \mathrm{OFF}, \mathrm{ON}, \mathrm{OFF}, \ldots$ etc as follows:

$$
\alpha_{\text {on }}=0, \frac{\pi}{2 \mathrm{~N}}, \frac{2 \pi}{2 \mathrm{~N}}, \frac{3 \pi}{2 \mathrm{~N}}, \frac{4 \pi}{2 \mathrm{~N}}, \ldots . . \text { etc. }
$$

(for 2-pulse with $50 \%$ duty cycle )

The experiential model is built using a zero-crossing detector to insure the synchronization with the input waveform.

\begin{tabular}{|l|l|}
\hline Item & Function \\
\hline AND Gate & $\begin{array}{l}\text { Buffer, level shutter and Q } \\
\text { driver }\end{array}$ \\
\hline Difference Amp. & $\begin{array}{l}\text { Isolation and grounding } \\
\text { elimination }(\mathrm{G}=1)\end{array}$ \\
\hline PLL & Frequency doubler \\
\hline Q & $\begin{array}{l}\text { Darlington transistor for } \\
\text { switching }\end{array}$ \\
\hline Zero Crossing Detector & Synchronization \\
\hline
\end{tabular}

Table 1. Experimental circuit component

The waveform of the rectifier output voltage, together with input and trigger signals are shown in Figure 11. 


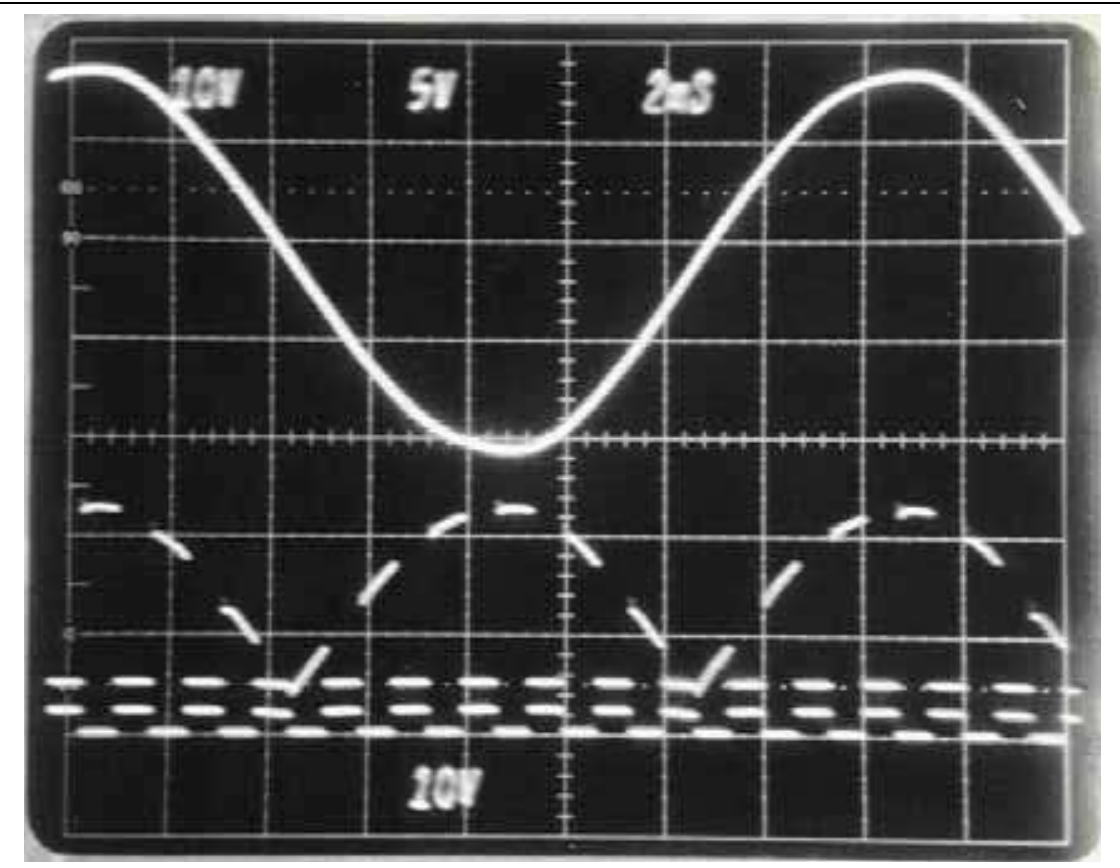

Fig. 10. Oscilloscope traces for input, trigger and output waveforms.

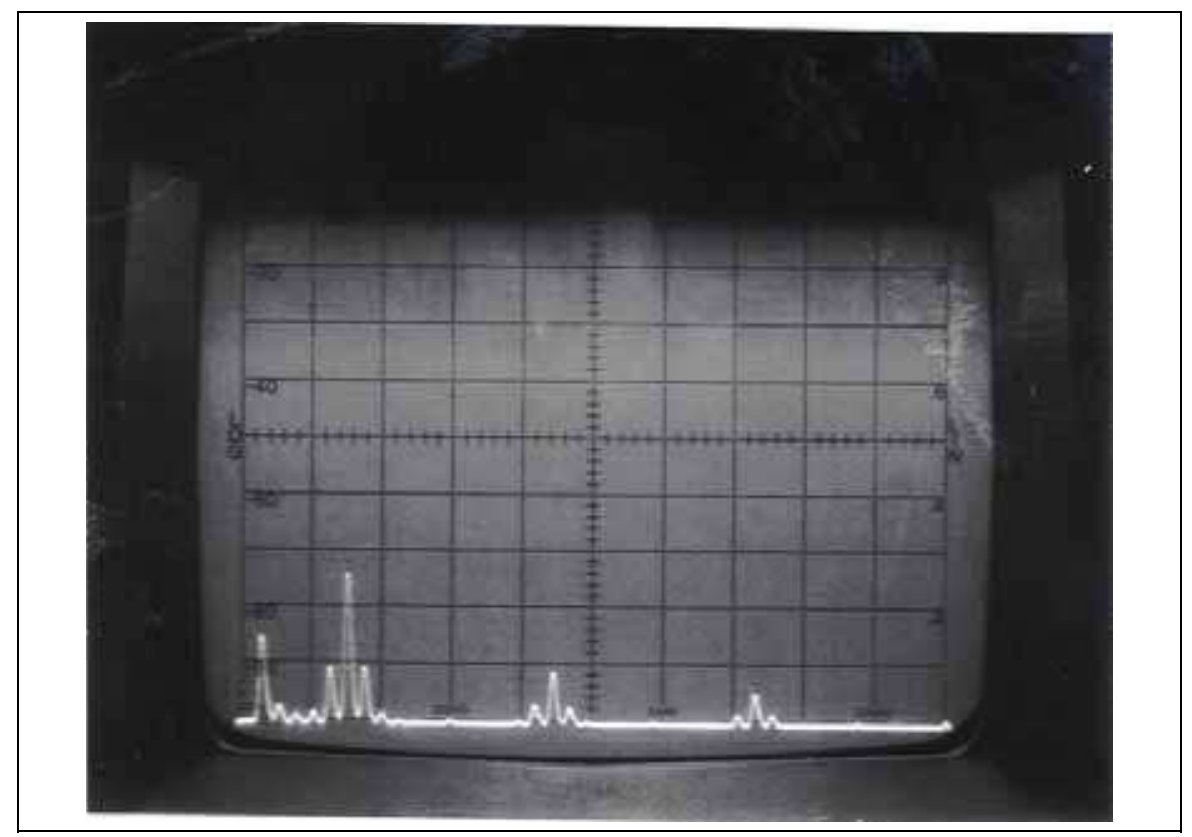

Fig. 11. Spectrum analyzer output for the output waveform. 
The comparison of the harmonic spectrum generated through the mathematical distribution, Pspice simulation, and the experimental verification is illustrated in figure 13. The figure depicts close agreement between the three methods. It shows clearly the generation of high order harmonics around the $720 \mathrm{~Hz}$.

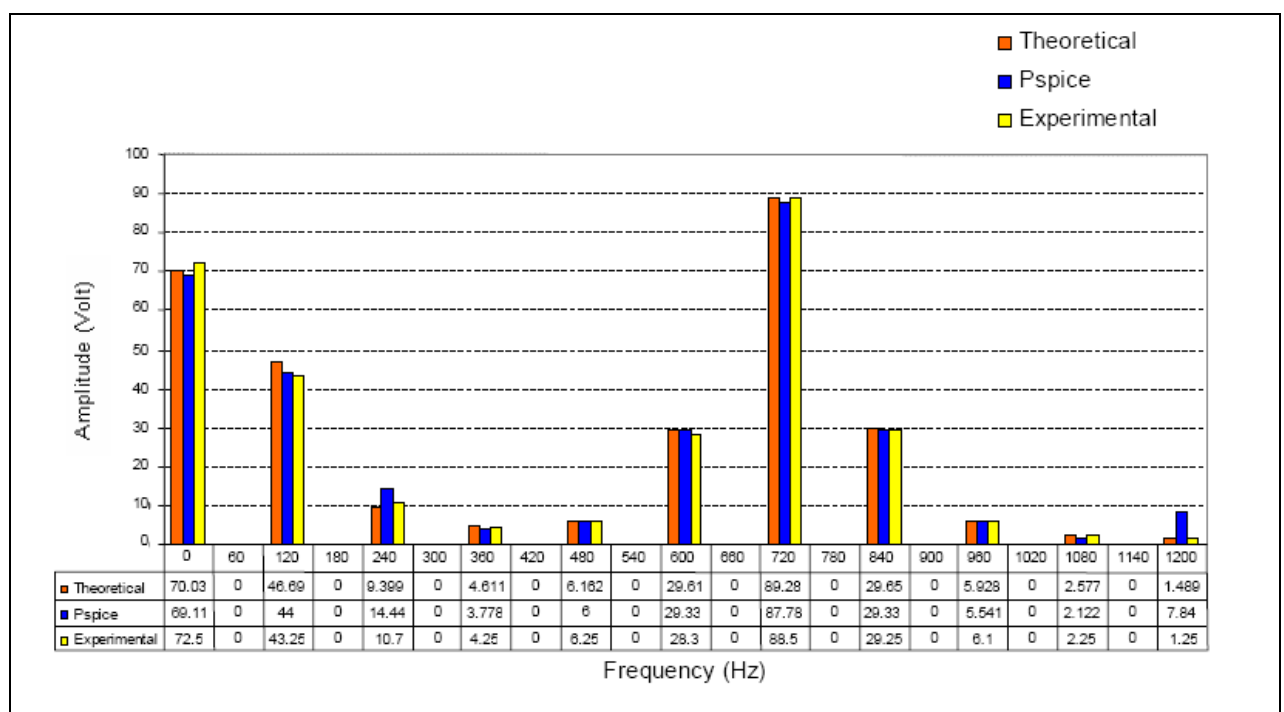

Fig. 12. Result comparison for the harmonic redistribution for the theoretical, simulation and experimental approaches.

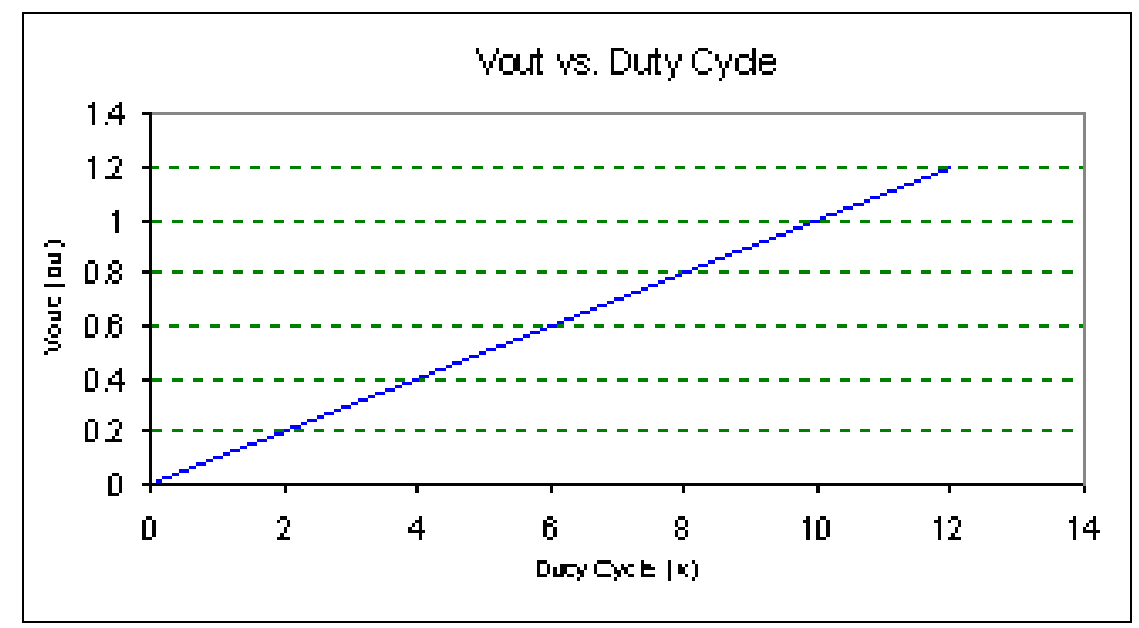

Fig. 13. The relation between the output voltage and the duty cycle 


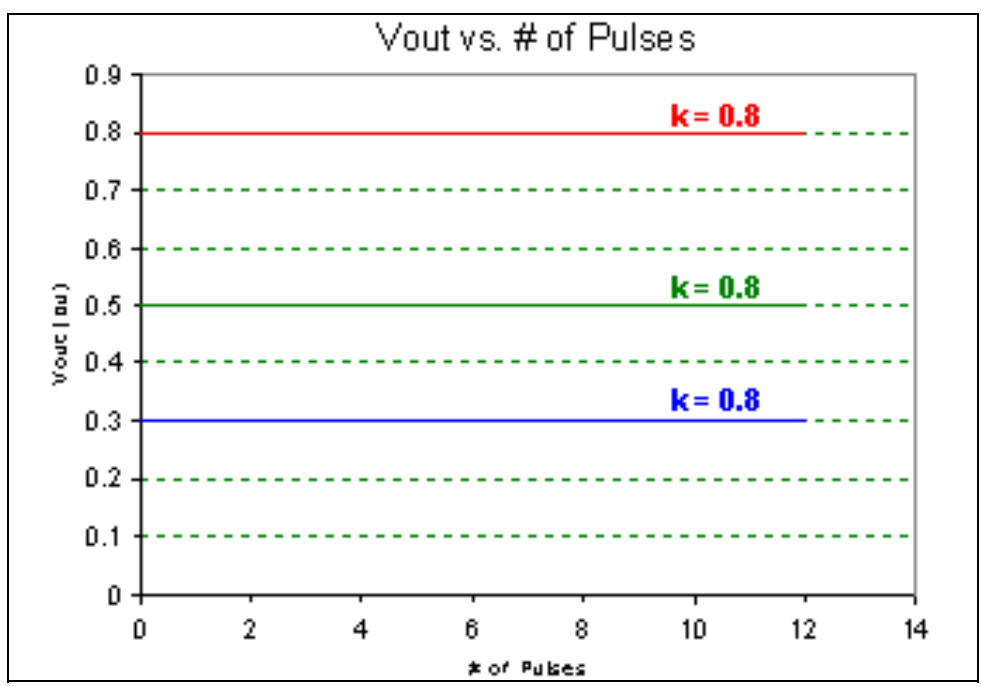

Fig. 14. The relation between the output voltage and the duty cycle

\section{Conclusion}

The chopping technique was verified as an efficient technique to reduce low-order (high amplitude) harmonics and shift them away from the fundamental at the DC side. Shifting the high amplitude harmonics to higher frequencies resulted in an easier, more effective filter design. The value of the DC average component is directly proportional to the duty cycle $\mathrm{k}$, while the number of PWMr pulses has no effect on the DC value. The highest harmonic amplitude is expected at the frequency equals to the fundamental frequency of the rectified voltage times number of pulses of PWM. The disadvantage of higher THD could be resolved by suppressing the high frequency components using low-pass filter.

\section{References}

Acoustics, Speech, and Signal Processing, 1999. ICASSP '99. Proceedings., 1999 IEEE International Conference Volume 4, 15-19 March 1999 Page(s):2263 - 2266 vol.4. Technique No 160 "harmonics uperstream rectifiers in UPS" .Jean Noël Fiorina Cahier

Ji Yanchao, Liang Xiaobing, Liu Zhuo, Jin Jisheng and Liu Xinhua . An Improved Passive Input Current Waveshaping Method for Single-phase Diode Rectifier. Industrial Electronics, Control, and Instrumentation, 1996., Proceedings of the 1996 IEEE IECON 22nd International Conference Volume 2, 5-10 Aug. 1996 Page(s):695 - 699 vol.2

Yazdian-Varjani, A.; Perera, S.; Chicharo, J.F. "A centroid-based PWM switching technique for full-bridge inverter applications" Power Electronics, IEEE Transactions Volume 13, Issue 1, Jan. 1998 Page(s):115 - 124. 


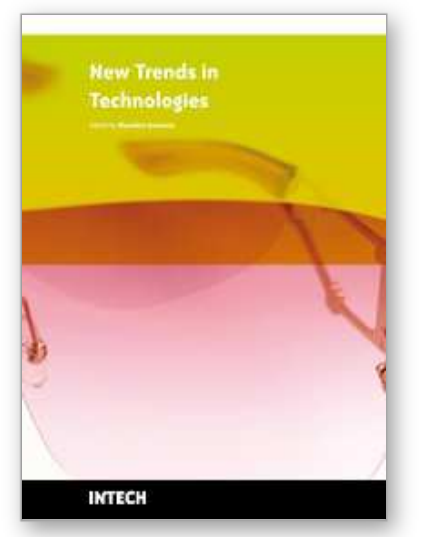

\section{New Trends in Technologies}

Edited by Blandna ramov

ISBN 978-953-7619-62-6

Hard cover, 242 pages

Publisher InTech

Published online 01, January, 2010

Published in print edition January, 2010

This book provides an overview of subjects in various fields of life. Authors solve current topics that present high methodical level. This book consists of 13 chapters and collects original and innovative research studies.

\section{How to reference}

In order to correctly reference this scholarly work, feel free to copy and paste the following:

Yahya Asiri and Ibrahim El-Amin (2010). Rectifier Low Order Harmonics Reduction Technique - Educational Approach, New Trends in Technologies, Blandna ramov (Ed.), ISBN: 978-953-7619-62-6, InTech, Available from: http://www.intechopen.com/books/new-trends-in-technologies/rectifier-low-order-harmonics-reductiontechnique-educational-approach

\section{INTECH}

open science | open minds

\section{InTech Europe}

University Campus STeP Ri

Slavka Krautzeka 83/A

51000 Rijeka, Croatia

Phone: +385 (51) 770447

Fax: +385 (51) 686166

www.intechopen.com

\section{InTech China}

Unit 405, Office Block, Hotel Equatorial Shanghai

No.65, Yan An Road (West), Shanghai, 200040, China

中国上海市延安西路65号上海国际贵都大饭店办公楼 405 单元

Phone: +86-21-62489820

Fax: $+86-21-62489821$ 
(C) 2010 The Author(s). Licensee IntechOpen. This chapter is distributed under the terms of the Creative Commons Attribution-NonCommercial-ShareAlike-3.0 License, which permits use, distribution and reproduction for non-commercial purposes, provided the original is properly cited and derivative works building on this content are distributed under the same license. 